\title{
Oral contraceptive use and mortality after 36 years of follow-up in the Nurses' Health Study: prospective cohort study
}

\author{
(C) $(1) \Theta$ OPEN ACCESS
}

\author{
Brittany M Charlton postdoctoral research fellow ${ }^{123}$, Janet W Rich-Edwards associate professor ${ }^{145}$, \\ Graham A Colditz professor ${ }^{6}$, Stacey A Missmer associate professor ${ }^{157}$, Bernard A Rosner \\ professor $^{5}$, Susan E Hankinson professor ${ }^{158}$, Frank E Speizer professor ${ }^{59}$, Karin B Michels associate \\ professor $^{1510}$
}

${ }^{1}$ Department of Epidemiology, Harvard School of Public Health, Boston, MA, USA; ${ }^{2}$ Division of Adolescent and Young Adult Medicine, Boston Children's Hospital, Boston, MA, USA; ${ }^{3}$ Department of Pediatrics, Harvard Medical School, Boston, MA, USA; ${ }^{4}$ Connors Center for Women's Health and Gender Biology, Brigham and Women's Hospital, Harvard Medical School, Boston, USA; ${ }^{5}$ Channing Division of Network Medicine, Department of Medicine, Brigham and Women's Hospital and Harvard Medical School, Boston, MA, USA; ${ }^{6}$ Department of Surgery, Washington University School of Medicine, St Louis, MO; ' Division of Reproductive Medicine, Brigham and Women's Hospital and Harvard Medical School, Boston, MA, USA; ${ }^{8}$ Division of Biostatistics and Epidemiology, School of Public Health and Health Sciences, University of Massachusetts, Amherst, MA, USA; ${ }^{9}$ Department of Environmental Health, Harvard School of Public Health, Boston, MA; ${ }^{10}$ Obstetrics and Gynecology Epidemiology Center, Department of Obstetrics, Gynecology and Reproductive Biology, Brigham and Women's Hospital and Harvard Medical School, Boston, MA, USA

\begin{abstract}
Objective To determine whether use of oral contraceptives is associated with all cause and cause specific mortality.

Design Prospective cohort study.

Setting Nurses' Health Study, data collected between 1976 and 2012.

Population 121701 participants were prospectively followed for 36 years; lifetime oral contraceptive use was recorded biennially from 1976 to 1982.

Main outcome measures Overall and cause specific mortality, assessed throughout follow-up until 2012. Cox proportional hazards models were used to calculate the relative risks of all cause and cause specific mortality associated with use of oral contraceptives.

Results In our population of 121577 women with information on oral contraceptive use, 63626 were never users (52\%) and 57951 were ever users (48\%). After 3.6 million person years, we recorded 31286 deaths. No association was observed between ever use of oral contraceptives and all cause mortality. However, violent or accidental deaths were more common among ever users (hazard ratio 1.20,95\% confidence interval 1.04 to 1.37). Longer duration of use was more strongly associated with certain causes of death, including premature mortality due to breast cancer (test for trend $\mathrm{P}<0.0001$ ) and decreased mortality rates of ovarian cancer $(\mathrm{P}=0.002)$. Longer time since last use
\end{abstract}

was also associated with certain outcomes, including a positive association with violent or accidental deaths $(\mathrm{P}=0.005)$.

Conclusions All cause mortality did not differ significantly between women who had ever used oral contraceptives and never users. Oral contraceptive use was associated with certain causes of death, including increased rates of violent or accidental death and deaths due to breast cancer, whereas deaths due to ovarian cancer were less common among women who used oral contraceptives. These results pertain to earlier oral contraceptive formulations with higher hormone doses rather than the now more commonly used third and fourth generation formulations with lower estrogen doses.

\section{Introduction}

Millions of women around the globe have used oral contraceptives since their debut in 1957, and oral contraceptives remain the most prescribed medication among US women aged 18-44. ${ }^{1}$ Oral contraceptives enable women to control their reproduction and thereby govern other aspects of their lives, such as career and family. Yet when oral contraceptives were made available, although acute side effects began to become apparent, no mechanism was in place to assess long term consequences. This was one of the main reasons the Nurses' Health Study was established. 
Numerous studies have weighed various health risks ${ }^{23}$ and benefits ${ }^{45}$ of oral contraceptive use, but it is only now, 50 years after oral contraceptives were first introduced, that the long term risks of the first generation and second generation oral contraceptives (defined by progestin type) can be studied. Since oral contraceptive use can affect various health outcomes through different mechanisms, mortality provides a uniquely relevant estimate by combining different causes of death.

These long term risks can only be estimated using large cohort studies with considerable follow-up..$^{6-9}$ Researchers from both the Oxford-Family Planning Association Contraceptive Study and the Royal College of General Practitioners' Oral Contraception Study have examined this topic. ${ }^{67}$ Further replication of these studies in other populations with even larger sample sizes are, however, needed to confirm these findings, especially among less common causes of death where more statistical power may be needed to detect differences.

We examined the association of oral contraceptive use and mortality after 36 years of follow-up in the Nurses' Health Study, which includes more than three times the number of participants and, because the participants are older, 18 times the total number of deaths as the Royal College of General Practitioners' Oral Contraception Study. Based on the previous cohort findings, we hypothesized that total mortality would be lower among women who ever used oral contraceptives. We also expected total mortality to decrease further with longer durations of oral contraceptive use and with more recent use.

\section{Methods}

\section{Study population}

The Nurses' Health Study was established in 1976 when 121 701 married female registered nurses 30-55 years of age completed a mailed questionnaire on their medical history and lifestyle factors. As one of the original intents of establishing the cohort was to examine the impact of oral contraceptive use on risk of breast cancer, and it was believed in 1976 that predominantly married women would be using oral contraceptives, the study was restricted to women who had previously in 1972 reported that they were married and were without a personal history of breast cancer. Follow-up questionnaires are sent biennially to participants, updating information on other risk factors and newly diagnosed diseases. Further details of the study have been described elsewhere. ${ }^{10}$ We excluded participants later determined ineligible for the study ( $\mathrm{n}=124)$ but no other exclusions were made, leaving 121 577 women in our baseline population.

\section{Assessment of exposure}

Information on oral contraceptive use, including starting and stopping dates, was collected on every questionnaire from 1976 until 1982, at which point less than $1 \%$ of the cohort reported oral contraceptive use. Participants reported all use of oral contraceptives, which therefore included use for contraceptive purposes and for other reasons, like endometriosis. We classified all 121577 women as never users or ever users, with no minimum use necessary to qualify as an ever user. We also calculated and updated the duration of use $(\leq 1,>1$ to $<2, \geq 2$ to $<5, \geq 5$ to $<10, \geq 10$ years) and time since last use $(\leq 4,>4$ to $<10, \geq 10$ to $<15, \geq 15$ years). Owing to missing data on these variables, we excluded 240 women from the analyses on duration of use and 2745 from the analyses of time since last use. For all regression analyses, we included dynamic use and potential confounding covariates as time varying variables (see supplementary file).
The reproducibility and validity of the data on oral contraceptives were evaluated in a study among 215 randomly selected participants from a similar study, the Nurses' Health Study II. ${ }^{11}$ We contrasted data from biennial questionnaires with data from a subsequent telephone interview that used a structured life events calendar. Agreement for ever use versus never use was $99 \%$, and the correlation for duration of use calculated from the two sources was 0.94 .

\section{Mortality ascertainment}

We assessed deaths from all causes between the return of the 1976 questionnaire and the end of follow-up (September 2012) using reports from families and by searching state mortality files and the National Death Index. ${ }^{12}$ Based on a validation study, we estimate that over $98 \%$ of deaths in our cohort have been ascertained. ${ }^{13}$ The cause of death was determined by reviewing the family reports, death certificates, and medical records. Deaths were grouped into six broad categories, according to ICD-8 (international classification of diseases, eighth revision) codes: cancer (ICD-8 codes 140-209), cardiovascular diseases (390-458), digestive diseases (520-577), violent/accidental (800-999, E808-999), other diseases (all codes, except those previously listed), and unconfirmed causes. Cause of death was further subdivided (for example, breast cancer, cervical cancer, uterine cancer) for additional analyses. These categories are consistent with those used in other analyses of oral contraceptive use and all cause mortality. ${ }^{74}$

\section{Assessment of covariate information}

We assessed information on covariates at baseline and during each biennial follow-up. Participants were asked at baseline about their date of birth and age at menarche. On the baseline and subsequent questionnaires we assessed weight; height; cigarette consumption; family medical history of breast, colon, and ovarian cancer as well as of heart disease; parity; age at first birth; hormone therapy use; duration of hormone therapy; history of benign breast disease; age at menopause; tubal ligation; and hysterectomy. Dietary intake, including alcohol, and current marital status were first accessed in 1980, physical activity in 1986, and race in 1992. We used the data from subsequent questionnaires to update information on the time varying covariates of calendar time, age, body mass index, smoking, alcohol intake, physical activity, marital status, hormone therapy use, duration of hormone therapy, history of benign breast disease, tubal ligation, and hysterectomy. Some of these covariates, such as hormone therapy use may have occurred only after oral contraceptive use ended (see supplementary file). Indicator variables were used for any missing information on covariates.

We categorized covariates as body mass index $(<21,21-22.9$, 23-24.9, 25-28.9, and $\geq 29$ ); cigarette smoking status (never, former, current); cigarette smoking amount and duration (continuous pack years); age at menarche $(<13,13,14, \geq 15$ years); alcohol intake (0, 0.1-9.9, 10-29.9, $\geq 30 \mathrm{~g} / \mathrm{d})$; physical activity $(<3,3-8.9,9-17.9,18-26.9, \geq 27$ metabolic equivalents of task (MET) h/wk); family history of breast, colon, and ovarian cancer (each yes, no); parity ( $0,1,2, \geq 3$ children); age at first birth ( $<24,24-25,26-29, \geq 30$ years); hormone therapy use (never, former, current); duration of hormone therapy $(0,0.1-<5$, $5-<10, \geq 10$ years); history of benign breast disease (yes, no); tubal ligation (yes, no); hysterectomy without bilateral oophorectomy (yes, no); family history of heart disease (yes, no); and marital status (married or domestic partnership, separated or divorced, widowed). The racial or ethnic 
composition of the cohort is predominantly white, so we categorized participants as white and non-white.

To increase efficiency we also examined risk factors previously shown to be statistically associated with mortality in this cohort $^{15}$ : body mass index at age $18\left(\right.$ per $\left.7 \mathrm{~kg} / \mathrm{m}^{2}\right)$; weight change since age 18 (per $23 \mathrm{~kg}$ ), from the 1980 questionnaire; height (per $15.2 \mathrm{~cm})$; nuts $(0, \leq 1, \geq 2$ servings per week), from the 1986 questionnaire; polyunsaturated fat (per 3\% energy), glycemic load (per 41 units), dietary cholesterol (per $105 \mathrm{mg} / 1000 \mathrm{kcal}$ ), and cereal fiber (per $4 \mathrm{~g}$, energy adjusted), based on the average values from 1980, 1984, and 1986 questionnaires; systolic blood pressure $(<120,120-139,140-149,150-159, \geq 160 \mathrm{~mm} \mathrm{Hg})$, from the 1986 questionnaire; use of antihypertensive drugs (yes, no), from the 1988 questionnaire; history of diabetes (yes, no), from the 2008 questionnaire or previous; myocardial infarction in a parent before age 60 (yes, no), from the 1988 questionnaire; and time since menopause (per 13 years) from the 1986 questionnaire. We modeled each of these variables as they were in the previously published model. ${ }^{15}$

\section{Statistical analyses}

We calculated person years of follow-up as the time from completion of the baseline questionnaire to the end of follow-up (September 2012), death, or loss to follow-up, whichever occurred first. Cox proportional hazards models, stratified jointly by age in months and calendar year of follow-up at the beginning of each two year questionnaire cycle, were used to calculate the relative risks (for example, hazard ratios) and $95 \%$ confidence intervals of all cause and cause specific mortality associated with oral contraceptive use for ever use or never use as well as for duration of use and time since last use.

Owing to the complexity of cause specific mortality, we used various adjustment strategies in our regression models. In model 1 we simultaneously adjusted for calendar time, age, body mass index, smoking status, and race. In model 2 we adjusted for the covariates in model 1 plus disease category risk factors. We adjusted cancers for age at menarche, alcohol intake, and physical activity, as well as a family history of breast, colon, and ovarian cancer. Cardiovascular diseases were adjusted for physical activity, alcohol intake, and family history of heart disease. Digestive diseases were adjusted for alcohol intake. We adjusted violent and accidental deaths for alcohol intake and marital status. In model 3 we adjusted for the covariates in model 2 plus mortality risk factors from a previous analysis conducted in this cohort. ${ }^{15}$

The causes of death from model 3 that were statistically related to oral contraceptive use, or even of borderline significance $(\mathrm{P}<0.08)$, were then further analyzed by duration of use and time since last use. We then analyzed these causes of death using a 10 year lag analysis; therefore, we excluded mortality cases during the 10 years between the last assessment of use and the beginning of follow-up. In additional analyses (model 4), we made further adjustments for disease specific confounders. For example, ovarian cancer analyses controlled for parity, tubal ligation, and hysterectomy, whereas breast cancer analyses controlled for parity, age at first birth, hormone therapy use, duration of hormone therapy, and history of benign breast disease.

All tests of statistical significance were two sided using $\mathrm{P}<0.05$. Trend tests were performed by modeling the medians of usage categories as continuous variables. Analyses were conducted with SAS software version 9.2. ${ }^{16}$

\section{Results}

In our population of 121577 women with information on oral contraceptive use, 63626 were never users (52.3\%) and 57951 were ever users $(47.7 \%)$ at last report on oral contraceptive use. Ever users reported a mean 4.1 years duration of use. Compared with never users at the midpoint of follow-up in 1994, ever users were more likely to have smoked, be younger at first birth, and have used hormone therapy (table $1 \Downarrow$ ).

After 36 years and 3.6 million person years of follow-up, we observed 31286 deaths (table $2 \Downarrow$ ): 11781 deaths from cancer, 6032 from cardiovascular disease, 855 from digestive disease, 1084 due to violence or accidents, 9212 from other diseases, and 4381 due to unconfirmed causes. As effect estimates did not vary greatly across the various adjustment models, results provided are from the most complete model (either model 3 or 4, depending on the cause of death).

Overall, all cause mortality did not significantly differ between women who had ever used oral contraceptives and those who had never used oral contraceptives. However, violent or accidental deaths were more common among ever users (hazard ratio $1.20,95 \%$ confidence interval 1.04 to 1.37 ), which was driven by suicide (1.41, 1.05 to 1.87$)$ compared with non-suicide violent or accidental deaths $(1.13,0.97$ to 1.32$)$. The association of oral contraceptive use with other causes of death, including breast cancer $(1.08,0.98$ to 1.18$)$, ovarian cancer $(0.86,0.74$ to $1.00)$, cerebrovascular disease $(0.90,0.80$ to 1.01$)$, and other diseases $(1.05,1.00$ to 1.10$)$, was of borderline statistical significance.

Longer duration of use (table $3 \Downarrow$ ) was more strongly associated with all cause mortality (test for trend $\mathrm{P}=0.02$ ) as well as with certain causes of death, including an increased rate for breast cancer $(\mathrm{P}<0.0001)$ and a decreased rate for ovarian cancer $(\mathrm{P}=0.002)$. Longer time since last use (table $4 \Downarrow$ ) was associated with increased all cause mortality $(\mathrm{P}=0.004)$ and certain outcomes such as violent or accidental deaths $(\mathrm{P}=0.005)$. The increased mortality from breast cancer was no longer significant with 10-14 years or 15 years or more since last use. In a 10 year lag analysis (table $5 \Downarrow$ ), deaths from breast cancer were no longer high, even with long durations of oral contraceptive use, but the test for trend was still significant. When stratifying deaths from breast cancer by hormone therapy use, oral contraceptive use was most strongly associated with these deaths in never users of hormone therapy. Violent or accidental deaths, including suicides, were no longer statistically associated with oral contraceptive use except with less than one year of use. Longer use continued to be associated with decreased mortality due to ovarian cancer $(\mathrm{P}=0.01)$.

\section{Discussion}

Ever use of oral contraceptives was not associated with all cause mortality but it was associated with specific causes of death, including an increased rate for deaths due to violence or accidents and breast cancer as well as a decreased rate due to ovarian cancer. Oral contraceptive use and mortality among participants in the Nurses' Health Study was previously examined, including a 12 year follow-up. ${ }^{9}$ In our previous analysis, no overall difference in mortality was seen in women who had used oral contraceptives compared with those who had never used oral contraceptives (hazard ratio $0.93,95 \%$ confidence interval 0.85 to 1.01$){ }^{9}{ }^{9}$ Our results did not materially change with an additional 24 years of follow-up, but we were able to examine more nuanced data on oral contraceptive use 
such as longer times since last use and to observe detailed findings in cause specific deaths.

\section{Comparisons to other studies}

Our results for all cause mortality confirm similar earlier findings from studies by the Royal College of General Practitioners and Oxford-Family Planning Association. Early reports from the Royal College of General Practitioners' Oral Contraception Study suggested a slight increase in all cause mortality ${ }^{17}$ with oral contraceptive use, but subsequent analyses reported no association or an inverse association. ${ }^{78}$ In the latest Royal College of General Practitioners' Oral Contraception Study analyses, the authors examined a subcohort that had more detailed information, and observed no association. ${ }^{19}$ Similarly, the Oxford-Family Planning Association Contraceptive Study reported a null finding, whereas a subsequent analysis identified a marginal inverse association. ${ }^{6}{ }^{20}$

Many of the cause specific results confirm previous findings in other cohorts as well. Increased breast cancer rates have been identified in previous reports, ${ }^{21-24}$ including the initial oral contraceptive and mortality analysis in the Nurses' Health Study, which specifically reported increased mortality due to breast cancer among current users. ${ }^{9}$ The inverse association of oral contraceptive use and the incidence of various gynecological cancers - for example, ovarian ${ }^{4}$ and uterine or endometrial ${ }^{25}$ - is well established. The Royal College of General Practitioners' Oral Contraception Study also identified increased rates of violent death among ever users. However, it is unlikely this is a causal association given the lack of a biological mechanism as well as inconsistent results in our other analyses, such as duration of oral contraceptive use with violent death.

Our data revealed some new results on duration of oral contraceptive use and time since last use. We observed increased all cause mortality with longer durations of use and longer times since last use, but the Royal College of General Practitioners' and Oxford-Family Planning Association studies did not see such trends. ${ }^{67}$ Increased deaths from breast cancer with longer durations of use, which is in line with the most recent meta-analysis, ${ }^{26}$ may explain the increasing all cause trend. Similarly, the inverse association with gynecologic cancers persists for many years after oral contraceptive use but seems to dissipate after more than 15 years since last oral contraceptive use. Using oral contraceptives for more than 15 years before the last assessment in 1982 may also be a marker for use of the earlier oral contraceptive formulations, which may have stronger effects given the high estrogen dose.

\section{Mechanisms}

The mechanisms by which oral contraceptives may affect various causes of death differ. With regard to cancer, estrogen binds to cell receptors, which upregulate hormone responsive genes and then promote DNA synthesis and cell proliferation. If a cell has cancer causing mutations, it can more easily proliferate and grow into a tumor. ${ }^{27}$ In addition, progestins can bind to different steroid receptors, which can lead to cell proliferation and cancer. ${ }^{28}$ The increased rates of violent or accidental deaths could be confounded by increased rates of intimate partner violence among ever users, since these women are more likely to be in relationships where violence could take place. ${ }^{29}$ Unfortunately, death records are not detailed enough to discern such information and confirm this hypothesis. With respect to suicides, an early analysis from the Royal College of General Practitioners' Oral Contraception Study found an increased rate in ever users, ${ }^{30}$ whereas later analyses ${ }^{7}$ as well as analyses in the Oxford-Family Planning Association Contraceptive Study ${ }^{18}$ reported null findings. The effect of oral contraceptives on mental health, including depression and mood changes, is not well understood but some of the most robust studies actually suggest a small but protective effect. ${ }^{31-34}$ Compared with more common causes of death, such as cardiovascular disease $(n=6032)$, the absolute risk of having a violent or accidental death $(\mathrm{n}=935)$, including by suicide $(n=234)$, is relatively low.

\section{Strengths and limitations of this study}

Previous literature has described the effect of oral contraceptive use on acute events. Some of these adverse events seem to be limited to current oral contraceptive users for diseases such as venous thromboembolism, stroke, and myocardial infarction. ${ }^{35}$ Because our follow-up began in 1976, after many participants had already initiated oral contraceptive use, we were not able to observe all acute events; therefore our results may be prone to some survivor bias (that is, a woman had to survive until 1976 to report her oral contraceptive use). These acute events were rare, even with earlier, higher dosed formulations of oral contraceptives, so this bias is unlikely to be strong.

The generalizability of our findings may be limited by the fact that our population was homogenous for race and generation or formulation of oral contraceptives. Most current oral contraceptives contain lower estrogen doses (20-35 $\mu \mathrm{g}$ of ethinyl estradiol) compared with oral contraceptives available in the 1950s through to the $80 \mathrm{~s}(50-150 \mu \mathrm{g}){ }^{36}{ }^{37}$ Though the estrogen dose is different from current oral contraceptives, there is more similarity in the type of progestin. For example, first generation and second generation oral contraceptives had debuted when our participants were taking these drugs, so they were exposed to both of these types of oral contraceptives, some of which are still prescribed, in addition to more third generation and fourth generation oral contraceptives. Older oral contraceptive formulations may still be in use in resource poor countries as well. It remains to be established whether newer low dose formulations have similar effects as the oral contraceptives that we studied. Nearly a dozen different types of progestins have been used in oral contraceptives since the $1950 \mathrm{~s}$, but we did not collect information on the different formulations in this cohort. In future analyses, new oral contraceptives need to be evaluated, especially because preliminary research indicates that some progestin types, such as triphasic preparations with levonorgestrel, may account for the increased risk of breast cancer. ${ }^{38}$ Most oral contraceptive formulations now combine estrogen and progestin, but in the 1950s and 60s, $20 \%$ of the market was made up of sequential oral contraceptives, in which each monthly cycle contained 16 estrogen pills followed by five estrogen plus progesterone pills. ${ }^{39}$ Oral contraceptive use today also differs in that long term use before pregnancy and extended use are more common now, owing to factors such as changing societal norms and pharmaceutical marketing. Finally, although oral contraceptive formulations have changed since the beginning of our study, our findings are still relevant especially since so many women who took these older formulations are still alive today.

Our study had several strengths. This is one of the largest cohorts with the longest follow-up to examine lifetime oral contraceptive use and mortality. The statistical power of our study enabled us to examine various cause specific deaths such as from cervical cancer, which is rare in this population. We were also able to adjust for numerous covariates, including exposure to other exogenous hormones such as hormone therapy use throughout follow-up, though this did not significantly impact the results. 
Hormone therapy use was reported more by ever users, so any hormone therapy effect would be more common in the ever user group. None the less, never users may have used other hormones such as fertility drugs and hormone therapy, so continuing to collect data in these large cohort studies will enable us to study long term effects of different periods of sex steroid use among all women, regardless of oral contraceptive history. The evolving literature on use of both oral contraceptives and hormone therapy will continue to illuminate the overall relation between sex steroid therapy and mortality. Follow-up rates in our cohort are high, with over $95 \%$ of participants being either actively followed or having a recorded death. Mortality ascertainment is over $98 \%$, so loss to follow-up or underestimating deaths is not likely to have biased our results. To identify potential confounding, we controlled for several covariates. We also conducted cause specific analyses with additional established risk factors for various causes of death, but our results did not appreciably change. Sensitivity analyses in other studies ${ }^{93}$ did not reveal important biases, which is reassuring and suggests that we are unlikely to have missed any major associations or confounding factors.

\section{Conclusions}

Overall, ever oral contraceptive use had no association with overall mortality but had diverse associations with cause specific mortality, including increased mortality from breast cancer and decreased mortality from ovarian cancer. Women who took first generation and second generation oral contraceptives through the early 1980 s can be reassured that this is unlikely to impact their mortality rate. These results primarily pertain to earlier formulations of oral contraceptives, though some of these (for example, second generation oral contraceptives, which include progestins such as levonorgestrel and norgestrel) are still commonly used but now with lower estrogen doses. However, these results may not apply to the now more commonly used third generation and fourth generation formulations.

In light of mortality analyses, the benefits of using oral contraceptives for both pregnancy prevention and non-contraceptive reasons should not be forgotten. Oral contraceptives help to ameliorate countless ailments, including dysmenorrhea, fibroid related symptoms, acne, and premenstrual dysphoric disorder. ${ }^{40}$ Oral contraceptive use also drastically reduces maternal mortality ${ }^{41}$ in several ways, including lowering the chance of pregnancy and its complications as well as reducing the risk of having an unsafe abortion. Even the first generation oral contraceptives had specific benefits, including a decrease in ovarian cysts and benign ovarian tumors. ${ }^{42-46} \mathrm{With}$ new contraceptive technologies, such as the vaginal ring and patch, as well as increasing use of intrauterine devices, ${ }^{47}$ it is imperative to understand the impact of exogenous sex steroids in contraceptives so that women can make informed decisions.

An abstract of this work was presented as an oral presentation at the annual meeting of the Society for Epidemiological Research on 28 June 2012. We thank the participants and staff of the Nurses' Health Study for their valuable contributions as well as the following state cancer registries for their help: AL, AZ, AR, CA, CO, CT, DE, FL, GA, ID, IL, IN, IA, KY, LA, ME, MD, MA, MI, NE, NH, NJ, NY, NC, ND, OH, OK, OR, PA, RI, SC, TN, TX, VA, WA, and WY.

Contributors: All authors conceived and designed the study. JWR-E, GAC, SAM, BAR, SEH, FES, and KBM acquired the data. BMC analyzed the data and wrote the manuscript while all authors critically reviewed the manuscript and approved the final version. All authors also had full access to all of the data (including statistical reports and tables) in the study and can take responsibility for the integrity of the data and the accuracy of the data analysis. The authors are not affiliated with the funding institutions. BMC and KBM act as the guarantors of the study.

Funding: The Nurses' Health Study was supported by research grants P01CA87969, R01HL034594, and R01HL088521 of the National Institutes of Health. BMC was supported by the training grant T32HD060454 in reproductive, perinatal, and pediatric epidemiology from the National Institute of Child Health and Human Development, and the training program in cancer epidemiology under grant T32CA09001 from the National Cancer Institute, National Institutes of Health. The funding sources had no role in study design; in the collection, analysis, and interpretation of data; in the writing of the report; or in the decision to submit the article for publication.

Competing interests: All authors have completed the ICMJE uniform disclosure form at www.icmje.org/coi_disclosure.pdf and declare: no support from any organisation for the submitted work; no financial relationships with any organisations that might have an interest in the submitted work in the previous three years; no other relationships or activities that could appear to have influenced the submitted work.

Ethical approval: This study was approved by the institutional review board of the Brigham and Women's Hospital in Boston, MA under protocol No 2010P001451. Informed consent was implied by the return of the baseline questionnaire.

Data sharing: Requests for access to data, statistical code, questionnaires, and technical processes may be made to the corresponding author at kmichels@research.bwh.harvard.edu.

Transparency: The lead author (BMC) affirms that the manuscript is an honest, accurate, and transparent account of the study being reported; that no important aspects of the study have been omitted; and that any discrepancies from the study as planned have been explained.

1 Cogliano V, Grosse Y, Baan R, Straif K, Secretan B, El Ghissassi F. Carcinogenicity of combined oestrogen-progestagen contraceptives and menopausal treatment. Lancet Oncol 2005;6:552-3.

2 Gillum LA, Mamidipudi SK, Johnston SC. Ischemic stroke risk with oral contraceptives: a meta-analysis. JAMA 2000;284:72-8.

3 Khader YS, Rice J, John L, Abueita O. Oral contraceptives use and the risk of myocardial infarction: a meta-analysis. Contraception 2003;68:11-7.

4 Beral V, Doll R, Hermon C, Peto R, Reeves G. Ovarian cancer and oral contraceptives: collaborative reanalysis of data from 45 epidemiological studies including 23,257 women with ovarian cancer and 87,303 controls. Lancet 2008;371:303-14.

5 Bosetti C, Bravi F, Negri E, La Vecchia C. Oral contraceptives and colorectal cancer risk: a systematic review and meta-analysis. Hum Reprod Update 2009;15:489-98.

6 Vessey M, Yeates D, Flynn S. Factors affecting mortality in a large cohort study with special reference to oral contraceptive use. Contraception 2010;82:221-9.

7 Hannaford PC, Iversen L, Macfarlane TV, Elliott AM, Angus V, Lee AJ. Mortality among contraceptive pill users: cohort evidence from Royal College of General Practitioners' Oral Contraception Study. BMJ 2010;340:c927.

8 Graff-Iversen S, Hammar N, Thelle DS, Tonstad S. Use of oral contraceptives and mortality during 14 years' follow-up of Norwegian women. Scand J Public Health 2006;34:11-6.

9 Colditz GA. Oral contraceptive use and mortality during 12 years of follow-up: the Nurses Health Study. Ann Intern Med 1994;120:821-6.

10 Belanger CF, Hennekens $\mathrm{CH}$, Rosner B, Speizer FE. The nurses' health study. Am J Nurs 1978;78:1039-40.

11 Hunter DJ, Manson JE, Colditz GA, Chasan-Taber L, Troy L, Stampfer MJ, et al. Reproducibility of oral contraceptive histories and validity of hormone composition reported in a cohort of US women. Contraception 1997;56:373-8.

12 Rich-Edwards JW, Corsano KA, Stampfer MJ. Test of the National Death Index and Equifax Nationwide Death Search. Am J Epidemiol 1994;140:1016-9.

13 Stampfer MJ, Willett WC, Speizer FE, Dysert DC, Lipnick R, Rosner B, et al. Test of the National Death Index. Am J Epidemiol 1984;119:837-9.

14 Beral V, Hermon C, Kay C, Hannaford P, Darby S, Reeves G. Mortality associated with oral contraceptive use: 25 year follow up of cohort of 46000 women from Royal College of General Practitioners' oral contraception study. BMJ 1999;318:96-100.

15 Baer HJ, Glynn RJ, Hu FB, Hankinson SE, Willett WC, Colditz GA, et al. Risk factors for mortality in the nurses' health study: a competing risks analysis. Am J Epidemiol 2011;173:319-29.

16 SAS Statistical Software, Release 9.2 [program]. Cary, NC: SAS Institute.

17 Further analyses of mortality in oral contraceptive users. Royal College of General Practitioners' Oral Contraception Study. Lancet 1981;1:541-6.

18 Vessey MP, Villard-Mackintosh L, McPherson K, Yeates D. Mortality among oral contraceptive users: 20 year follow up of women in a cohort study. BMJ 1989;299:1487-91.

19 Brind J. Mortality and the pill. Wrong conclusions drawn, again. BMJ 2010;340:c2523.

20 Vessey M, Painter R, Yeates D. Mortality in relation to oral contraceptive use and cigarette smoking. Lancet 2003;362:185-91.

21 Kahlenborn C, Modugno F, Potter DM, Severs WB. Oral contraceptive use as a risk factor for premenopausal breast cancer: a meta-analysis. Mayo Clin Proc 2006;81:1290-302.

22 Breast cancer and combined oral contraceptives: results from a multinational study. The WHO Collaborative Study of Neoplasia and Steroid Contraceptives. Br J Cancer 1990;61:110-9. 


\section{What is already known on this topic}

Oral contraceptives are the most prescribed medication among US women of reproductive age

Oral contraceptive use reduces some health risks, like ovarian cancer, but increases others, like venous thromboembolism

The long term risks of using oral contraceptives, including mortality, remain unclear

\section{What this study adds}

All cause mortality did not significantly differ between women who had ever used oral contraceptives and those who had never used oral contraceptives

However, oral contraceptive use was associated with certain causes of death, including increased violent or accidental and breast cancer related deaths and decreased mortality from ovarian cancer

23 Rookus MA, van Leeuwen FE. Oral contraceptives and risk of breast cancer in women aged 20-54 years. Netherlands Oral Contraceptives and Breast Cancer Study Group. Lancet 1994;344:844-51.

24 Breast cancer and hormonal contraceptives: further results. Collaborative Group on Hormonal Factors in Breast Cancer. Contraception 1996;54(3 Suppl):1S-106S.

25 Mueck AO, Seeger H, Rabe T. Hormonal contraception and risk of endometrial cancer: a systematic review. Endocr Relat Cancer 2010:17:R263-71.

26 Zhu H, Lei X, Feng J, Wang Y. Oral contraceptive use and risk of breast cancer: a meta-analysis of prospective cohort studies. Eur J Contracept Reprod Health Care 2012;17:402-14.

27 Gruber CJ, Tschugguel W, Schneeberger C, Huber JC. Production and actions of estrogens. N Engl J Med 2002;346:340-52.

28 Pasqualini JR. Progestins and breast cancer. Gynecol Endocrinol 2007:23(Suppl 1):32-41.

29 Fanslow J, Whitehead A, Silva M, Robinson E Contraceptive use and associations with intimate partner violence among a population-based sample of New Zealand women. Aust N Z J Obstet Gynaecol 2008;48:83-9.

30 Kay CR. The Royal College of General Practitioners' Oral Contraception Study: some recent observations. Clin Obstet Gynaecol 1984;11:759-86.

31 Kahn LS, Halbreich U. Oral contraceptives and mood. Expert Opin Pharmacother 2001;2:1367-82.

32 Keyes KM, Cheslack-Postava K, Westhoff C, Heim CM, Haloossim M, Walsh K, et al. Association of hormonal contraceptive use with reduced levels of depressive symptoms: a national study of sexually active women in the United States. Am J Epidemiol 2013;178:1378-88

33 Oinonen KA, Mazmanian D. To what extent do oral contraceptives influence mood and affect? J Affect Disord 2002;70:229-40.

34 Toffol E, Heikinheimo O, Koponen P, Luoto R, Partonen T. Hormonal contraception and mental health: results of a population-based study. Hum Reprod 2011;26:3085-93.

35 Vessey MP. Oral contraception and health. Br J Gen Pract 1998;48:1639-40.

36 Annegers JF. Patterns of oral contraceptive use in the United States. Br J Rheumatol 1989;28(Suppl 1):48-50.

37 Piper JM, Kennedy DL. Oral contraceptives in the United States: trends in content and potency. Int J Epidemiol 1987;16:215-21.
38 Hunter DJ, Colditz GA, Hankinson SE, Malspeis S, Spiegelman D, Chen W, et al. Ora contraceptive use and breast cancer: a prospective study of young women. Cancer Epidemiol Biomarkers Prev 2010;19:2496-502.

39 Hankinson SE, Colditz GA, Manson JE, Willett WC, Hunter DJ, Stampfer MJ, et al. A prospective study of oral contraceptive use and risk of breast cancer (Nurses' Health Study, United States). Cancer Causes Control 1997;8:65-72.

40 Maguire K, Westhoff $\mathrm{C}$. The state of hormonal contraception today: established and emerging noncontraceptive health benefits. Am J Obstet Gynecol 2011;205(4 Suppl):S4-8.

41 Ahmed S, Li Q, Liu L, Tsui AO. Maternal deaths averted by contraceptive use: an analysis of 172 countries. Lancet 2012;380:111-25.

42 Egarter C, Putz M, Strohmer H, Speiser P, Wenzl R, Huber J. Ovarian function during low-dose oral contraceptive use. Contraception 1995;51:329-33.

43 Young RL, Snabes MC, Frank ML, Reilly M. A randomized, double-blind, placebo-controlled comparison of the impact of low-dose and triphasic oral contraceptives on follicular development. Am J Obstet Gynecol 1992;167:678-82.

44 Lanes SF, Birmann B, Walker AM, Singer S. Oral contraceptive type and functional ovarian cysts. Am J Obstet Gynecol 1992;166:956-61.

45 Caillouette JC, Koehler AL. Phasic contraceptive pills and functional ovarian cysts. Am J Obstet Gynecol 1987;156:1538-42.

46 Functional ovarian cysts and oral contraceptives. Negative association confirmed surgically. A cooperative study. JAMA 1974;228:68-9.

47 Mosher WD, Jones J. Use of contraception in the United States: 1982-2008. Vital Health Stat 23 2010:1-44

\section{Accepted: 4 October 2014}

\section{Cite this as: BMJ 2014;349:g6356}

This is an Open Access article distributed in accordance with the Creative Commons Attribution Non Commercial (CC BY-NC 4.0) license, which permits others to distribute, remix, adapt, build upon this work non-commercially, and license their derivative works on different terms, provided the original work is properly cited and the use is non-commercial. See: http://creativecommons.org/licenses/by-nc/4.0/. 


\section{Tables}

Table 1| Age standardized characteristics of ever and never users of oral contraceptives among 121577 participants in the Nurses' Health Study at midpoint of follow-up (1994), 1976-2012. Values are percentages (number of participants) unless stated otherwise

\begin{tabular}{|c|c|c|}
\hline Characteristics & Never users ( $n=63626$ ) & Ever users $(n=57951)$ \\
\hline \multicolumn{3}{|l|}{ Base model (model 1) } \\
\hline Mean (SD) age (years) & $61.2(7.1)$ & $60.8(7.1)$ \\
\hline Mean (SD) BMI $\left(\mathrm{kg} / \mathrm{m}^{2}\right)$ & $26.6(5.1)$ & $26.3(5.0)$ \\
\hline Mean (SD) smoking amount and duration (pack years) & $11.9(19.0)$ & $13.1(19.8)$ \\
\hline \multicolumn{3}{|l|}{ Smoking status*: } \\
\hline Never & $43(27423)$ & $39(22775)$ \\
\hline Former & $36(23096)$ & $39(22717)$ \\
\hline Current & $12(7762)$ & $13(7592)$ \\
\hline \multicolumn{3}{|l|}{ Race*: } \\
\hline White & 77 (49 183) & $80(46477)$ \\
\hline Non-white & $8(5154)$ & $7(4230)$ \\
\hline \multicolumn{3}{|l|}{ Disease category risk factors (model 2) } \\
\hline Mean (SD) age at menarche (years) & $12.4(1.8)$ & $12.5(1.8)$ \\
\hline Mean (SD) alcohol intake (g/day) & $4.5(8.6)$ & $5.5(9.7)$ \\
\hline Mean (SD) physical activity (MET h/wk) & $19.5(25.0)$ & $19.6(24.4)$ \\
\hline \multicolumn{3}{|l|}{ Marital status* + : } \\
\hline Married or in domestic partnership & $56(35821)$ & 59 (34 365) \\
\hline Separated or divorced & $5(3372)$ & $7(4172)$ \\
\hline Widowed & $11(7126)$ & $10(5853)$ \\
\hline \multicolumn{3}{|l|}{ Family history: } \\
\hline Breast cancer & $13(8335)$ & $14(8345)$ \\
\hline Colon cancer & $12(7826)$ & $12(7070)$ \\
\hline Ovarian cancer & $2(1336)$ & $2(1217)$ \\
\hline Heart disease & 77 (49 247) & $79(45955)$ \\
\hline \multicolumn{3}{|l|}{ Mortality risk factors (model 3 ) } \\
\hline Mean (SD) BMI at age $18\left(\mathrm{~kg} / \mathrm{m}^{2}\right)$ & $21.4(2.7)$ & $21.2(2.7)$ \\
\hline Mean (SD) weight change since age $18(\mathrm{~kg})$ & $7.1(12.3)$ & $6.7(11.8)$ \\
\hline Mean (SD) height $(\mathrm{cm})$ & $163.8(6.1)$ & $163.8(6.1)$ \\
\hline Mean (SD) nut consumption (servings/wk) $\ddagger$ & $0.7(1.9)$ & $0.7(2.0)$ \\
\hline Mean (SD) polyunsaturated fat (\% energy) $\ddagger$ & $5.7(1.1)$ & $5.7(1.1)$ \\
\hline Mean (SD) glycemic load (GL units) $\ddagger$ & $100.0(17.0)$ & $98.8(16.7)$ \\
\hline Mean (SD) dietary cholesterol (mg/1000 kJ per day) $\ddagger$ & $686.2(188.3)$ & $690.4(188.3)$ \\
\hline Mean (SD) cereal fiber (g/d energy adjusted) $\ddagger$ & $4.2(1.9)$ & $4.3(2.0)$ \\
\hline Mean (SD) systolic blood pressure $(\mathrm{mm} \mathrm{Hg})^{*}$ & $130.0(15.0)$ & $129.0(15.0)$ \\
\hline Use of antihypertensive drugs & $22(14125)$ & $24(14082)$ \\
\hline History of diabetes & $7(4517)$ & $7(4172)$ \\
\hline Parental myocardial infarction before age 60 & $17(10944)$ & $18(10605)$ \\
\hline Mean (SD) time since menopause (years) & $11.6(8.6)$ & $11.0(7.9)$ \\
\hline \multicolumn{3}{|l|}{ Disease risk factors (model 4) } \\
\hline Mean (SD) age at first birth (years) $\dagger$ & $32.5(22.0)$ & $29.8(18.1)$ \\
\hline Mean (SD) parity $\dagger$ & $2.9(1.7)$ & $3.1(1.6)$ \\
\hline Mean (SD) duration of hormone therapy (years) & $3.0(5.4)$ & $3.8(5.5)$ \\
\hline \multicolumn{3}{|l|}{ Hormone therapy use*: } \\
\hline Premenopausal & $12(7699)$ & $11(6433)$ \\
\hline Never & $26(16670)$ & $20(11706)$ \\
\hline
\end{tabular}




\section{Table 1 (continued)}

\section{Characteristics}

Never users ( $n=63626)$ Ever users $(n=57951)$

\begin{tabular}{lcc} 
Former & $15(9671)$ & $17(9910)$ \\
\hline Current & $28(18006)$ & $36(20978)$ \\
\hline Tubal ligation & $15(9671)$ & $20(11764)$ \\
\hline Hysterectomy without bilateral oophorectomy & $13(8462)$ & $15(8924)$ \\
\hline History of benign breast disease & $42(26850)$ & $44(25672)$ \\
\hline
\end{tabular}

$\mathrm{BMI}=$ body mass index; MET=metabolic equivalent of task.

*May not add to $100 \%$ owing to missing data.

†Assessed in 1996.

$\ddagger$ Average of dietary values through 1994 . 
Table 2| Total and cause specific mortality in ever and never users of oral contraceptives among 121577 participants in the Nurses' Health Study, 1976-2012

\begin{tabular}{|c|c|c|c|c|c|c|}
\hline \multirow[t]{2}{*}{ Cause of death } & \multirow[b]{2}{*}{ ICD-8 codes } & \multirow[b]{2}{*}{ Never users } & \multirow[b]{2}{*}{ Ever users } & \multicolumn{3}{|c|}{ Hazard ratio $(95 \% \mathrm{Cl})$} \\
\hline & & & & Model 1* & $\begin{array}{l}\text { Model 2+disease } \\
\text { category risk factors } †\end{array}$ & $\begin{array}{c}\text { Model 3+mortality risk } \\
\text { factors } \neq\end{array}$ \\
\hline All causes & $\begin{array}{c}000 \text { to } 999, \text { all } \mathrm{E} \\
\text { codes }\end{array}$ & 20646 & 10640 & 1.01 (0.98 to 1.03$)$ & - & 1.02 (0.99 to 1.04$)$ \\
\hline All cancers: & 140 to 209 & 7420 & 4361 & 1.00 (0.96 to 1.04$)$ & $1.01(0.97$ to 1.05$)$ & $1.01(0.97$ to 1.05$)$ \\
\hline $\begin{array}{l}\text { Large bowel and } \\
\text { rectum }\end{array}$ & 153 to 154 & 693 & 361 & 0.95 (0.83 to 1.09$)$ & $0.97(0.84$ to 1.11$)$ & $0.97(0.84$ to 1.11$)$ \\
\hline Gallbladder/liver & 155 to 156 & 158 & 90 & 0.96 (0.73 to 1.28$)$ & $0.98(0.74$ to 1.30$)$ & $0.98(0.74$ to 1.30$)$ \\
\hline Lung & 162 & 1637 & 1007 & 1.05 (0.96 to 1.14$)$ & 1.05 (0.96 to 1.14$)$ & $1.05(0.97$ to 1.14$)$ \\
\hline Melanoma & 172 & 111 & 58 & 0.77 (0.55 to 1.09$)$ & 0.76 (0.54 to 1.07$)$ & 0.76 (0.54 to 1.08$)$ \\
\hline Breast & 174 & 1387 & 908 & 1.09 (0.99 to 1.20$)$ & 1.09 (0.99 to 1.20$)$ & $1.08(0.98$ to 1.18$)$ \\
\hline Cervical & 180 & 30 & 18 & $1.00(0.52$ to 1.92$)$ & $1.01(0.52$ to 1.96$)$ & 1.04 (0.54 to 2.02$)$ \\
\hline Uterine/endometrial & 182 & 224 & 111 & 0.79 (0.61 to 1.02$)$ & $0.81(0.63$ to 1.04$)$ & $0.81(0.63$ to 1.03$)$ \\
\hline Ovarian & 183 & 538 & 314 & 0.87 (0.75 to 1.02$)$ & 0.88 (0.76 to 1.02$)$ & $0.86(0.74$ to 1.00$)$ \\
\hline CNS-pituitary & 191,194 & 214 & 141 & $1.03(0.81$ to 1.30$)$ & $1.04(0.82$ to 1.31$)$ & 1.05 (0.83 to 1.33 ) \\
\hline Site unknown & 199 & 443 & 231 & 0.95 (0.80 to 1.12$)$ & $0.95(0.80$ to 1.13$)$ & 0.94 (0.79 to 1.12$)$ \\
\hline Other cancers & $\begin{array}{c}140 \text { to } 209 \text {, except } \\
\text { above }\end{array}$ & 1985 & 1122 & 1.01 (0.93 to 1.09$)$ & $1.02(0.94$ to 1.11$)$ & $1.03(0.95$ to 1.11$)$ \\
\hline $\begin{array}{l}\text { All cardiovascular } \\
\text { diseases: }\end{array}$ & 390 to 458 & 4257 & 1775 & 0.98 (0.92 to 1.04$)$ & $1.00(0.94$ to 1.06$)$ & $1.00(0.94$ to 1.06$)$ \\
\hline Ischemic heart disease & 410 to 414 & 1857 & 789 & 1.02 (0.94 to 1.12$)$ & 1.04 (0.95 to 1.14$)$ & 1.04 (0.95 to 1.14$)$ \\
\hline Other heart & 420 to 429 & 629 & 259 & $0.96(0.81$ to 1.12$)$ & 0.97 (0.83 to 1.13$)$ & 0.96 (0.82 to 1.12$)$ \\
\hline $\begin{array}{l}\text { Cerebrovascular } \\
\text { disease }\end{array}$ & 430 to 438 & 1196 & 445 & $0.89(0.79$ to 1.00$)$ & $0.90(0.80$ to 1.01$)$ & $0.90(0.80$ to 1.01$)$ \\
\hline Thromboembolic & $\begin{array}{c}444 \text { to } 445,451 \text { to } \\
453\end{array}$ & 104 & 52 & 1.05 (0.74 to 1.50$)$ & 1.07 (0.75 to 1.52$)$ & $1.06(0.74$ to 1.51$)$ \\
\hline Other circulatory & $\begin{array}{l}390 \text { to } 409,440 \text { to } \\
458 \text {, except above }\end{array}$ & 471 & 230 & 1.06 (0.90 to 1.26$)$ & 1.08 (0.91 to 1.28$)$ & $1.10(0.93$ to 1.31$)$ \\
\hline All digestive diseases: & 520 to 577 & 549 & 306 & 1.07 (0.92 to 1.24$)$ & $1.07(0.91$ to 1.24$)$ & 1.10 (0.95 to 1.28$)$ \\
\hline Liver disease & 570 to 573 & 226 & 153 & 1.14 (0.91 to 1.42$)$ & $1.12(0.90$ to 1.41$)$ & 1.15 (0.91 to 1.44$)$ \\
\hline Violence/accidents & 800 to 999 , E808-999 & 640 & 444 & 1.20 (1.05 to 1.37$)$ & $1.18(1.03$ to 1.35$)$ & $1.20(1.04$ to 1.37$)$ \\
\hline Suicide & E950-959 & 111 & 130 & $1.43(1.08$ to 1.90$)$ & $1.42(1.07$ to 1.88$)$ & 1.41 (1.05 to 1.87$)$ \\
\hline Other diseases & $\begin{array}{c}\text { All codes, except } \\
\text { above }\end{array}$ & 6182 & 3030 & 1.03 (0.98 to 1.08$)$ & - & $1.05(1.00$ to 1.10$)$ \\
\hline Unconfirmed & NA & 2916 & 1465 & 0.95 (0.89 to 1.02$)$ & - & 0.98 (0.91 to 1.04$)$ \\
\hline
\end{tabular}

$\mathrm{NA}=$ not available.

*Adjusts for calendar time, age, body mass index, race, smoking status, and smoking amount/duration, with never users as reference.

†Adjusts for variables in model 1 and further adjusts for disease category risk factors. Cancers are adjusted for age at menarche, alcohol intake, physical activity, and family history of breast, colon, and ovarian cancer. Cardiovascular diseases are adjusted for alcohol intake, physical activity, and family history of heart disease. Digestive diseases are adjusted for alcohol intake. Violent/accidental deaths are adjusted for alcohol intake and marital status.

¥Adjusts for variables in model 2 and further adjusts for mortality risk factors, including body mass index at age 18, weight change since age 18 , height, alcohol intake, physical activity, nut consumption, polyunsaturated fat, glycemic load, dietary cholesterol, cereal fiber, systolic blood pressure, use of antihypertensive drugs, personal history of diabetes, parental myocardial infarction before age 60 , and time since menopause. 
Table 3| Hazard ratios (95\% confidence intervals) of total and cause specific mortality by duration of oral contraceptive use (years) compared with never users among 121337 participants in the Nurses' Health Study, 1976-2012

\begin{tabular}{|c|c|c|c|c|c|c|}
\hline \multirow[b]{2}{*}{ Cause of death } & \multicolumn{5}{|c|}{ Duration of oral contraceptive use (years) } & \multirow[b]{2}{*}{ P for trenc } \\
\hline & $\leq 1$ & $>1$ to $<2$ & $\geq 2$ to $<5$ & $\geq 5$ to $<10$ & $\geq 10$ & \\
\hline All causes ${ }^{*}(n=31237)$ & $1.01(0.97$ to 1.05$)$ & $1.01(0.94$ to 1.08$)$ & $1.02(0.97$ to 1.06$)$ & $1.05(1.00$ to 1.09$)$ & $1.05(0.99$ to 1.12$)$ & 0.02 \\
\hline Breast cancer† $(n=2295)$ & $1.06(0.93$ to 1.22$)$ & $1.05(0.84$ to 1.33$)$ & $1.03(0.89$ to 1.21$)$ & $1.20(1.03$ to 1.40$)$ & $1.27(1.03$ to 1.56$)$ & 0.003 \\
\hline $\begin{array}{l}\text { Breast cancer, further } \\
\text { adjusted } \ddagger\end{array}$ & $1.05(0.91$ to 1.21$)$ & $1.06(0.84$ to 1.33$)$ & $1.05(0.90$ to 1.23$)$ & 1.26 (1.09 to 1.46$)$ & $1.39(1.13$ to 1.71$)$ & $<0.0001$ \\
\hline Ovarian cancert $(n=851)$ & $0.89(0.70$ to 1.12$)$ & $0.96(0.67$ to 1.39$)$ & 0.99 (0.78 to 1.25$)$ & $0.70(0.53$ to 0.92$)$ & 0.60 (0.39 to 0.92$)$ & 0.002 \\
\hline $\begin{array}{l}\text { Ovarian cancer, further } \\
\text { adjusted§ }\end{array}$ & $0.89(0.71$ to 1.12$)$ & 0.96 (0.67 to 1.39$)$ & $0.98(0.77$ to 1.25$)$ & 0.69 (0.53 to 0.92$)$ & $0.60(0.40$ to 0.93$)$ & 0.002 \\
\hline $\begin{array}{l}\text { Cerebrovascular } \\
\text { disease } \mathbb{( n = 1 6 3 9 )}\end{array}$ & $0.73(0.60$ to 0.90$)$ & $0.89(0.63$ to 1.25$)$ & $0.89(0.72$ to 1.11$)$ & 0.98 (0.79 to 1.19$)$ & $1.21(0.94$ to 1.56$)$ & 0.26 \\
\hline $\begin{array}{l}\text { Violence/accidents }{ }^{* *} \\
(\mathrm{n}=1083)\end{array}$ & 1.35 (1.12 to 1.64$)$ & $0.81(0.55$ to 1.19$)$ & $1.12(0.90$ to 1.40$)$ & $0.94(0.74$ to 1.20$)$ & $1.13(0.83$ to 1.55$)$ & 0.94 \\
\hline Suicide $^{* *}(n=240)$ & 1.36 (0.91 to 2.02$)$ & $0.99(0.51$ to 1.93$)$ & 1.55 (1.05 to 2.30$)$ & 0.84 (0.51 to 1.39$)$ & 1.83 (1.07 to 3.15$)$ & 0.26 \\
\hline Other diseases ${ }^{*}(n=9195)$ & 1.05 (0.98 to 1.14$)$ & $1.02(0.89$ to 1.16$)$ & $1.04(0.96$ to 1.13$)$ & $1.05(0.97$ to 1.14$)$ & $1.11(1.00$ to 1.24$)$ & 0.04 \\
\hline
\end{tabular}

*Adjusts for model 3 variables: base model+mortality risk factors.

†Adjusts for model 3 variables: base model+cancer risk factors+mortality risk factors.

$\ddagger$ Adjusts for model 4 variables: base model+cancer risk factors+mortality risk factors+breast cancer risk factors (parity, age at first birth, hormone therapy use,

duration of hormone therapy, and history of benign breast disease).

§Adjusts for model 4 variables: base model+cancer risk factors+mortality risk factors+ovarian cancer risk factors (parity, tubal ligation, and hysterectomy).

TAdjusts for model 3 variables: sociodemographics+cardiovascular risk factors+mortality risk factors.

${ }^{* \star}$ Adjusts for model 3 variables: sociodemographics+violent/accident death risk factors+mortality risk factors. 
Table 4| Hazard ratios (95\% confidence intervals) of total and cause specific mortality by time since last oral contraceptive use (years) compared with never users among 118832 Nurses' Health Study participants, 1976-2012

\begin{tabular}{|c|c|c|c|c|c|}
\hline \multirow[b]{2}{*}{ Cause of death } & \multicolumn{4}{|c|}{ Time since last oral contraceptive use (years) } & \multirow[b]{2}{*}{ P for trend } \\
\hline & $\leq 4$ & $>4$ to $<10$ & $\geq 10$ to $<15$ & $\geq 15$ & \\
\hline All causes ${ }^{*}(n=30541)$ & 0.97 (0.92 to 1.02$)$ & $1.02(0.98$ to 1.06$)$ & $1.04(1.00$ to 1.08$)$ & $1.06(1.01$ to 1.10$)$ & 0.004 \\
\hline Breast cancer† $(n=2253)$ & $1.01(0.84$ to 1.21$)$ & 1.19 (1.04 to 1.37$)$ & $1.10(0.96$ to 1.26$)$ & 1.09 (0.93 to 1.29$)$ & 0.05 \\
\hline $\begin{array}{l}\text { Breast cancer, further } \\
\text { adjusted } \ddagger\end{array}$ & 1.07 (0.89 to 1.28$)$ & $1.23(1.07$ to 1.42$)$ & $1.13(0.98$ to 1.29$)$ & $1.09(0.92$ to 1.28$)$ & 0.04 \\
\hline Ovarian cancer† $(n=827)$ & $0.76(0.56$ to 1.04$)$ & $0.61(0.46$ to 0.80$)$ & $0.97(0.78$ to 1.20$)$ & $1.04(0.81$ to 1.33$)$ & 0.69 \\
\hline $\begin{array}{l}\text { Ovarian cancer, further } \\
\text { adjusted§ }\end{array}$ & 0.77 (0.56 to 1.05$)$ & 0.61 (0.47 to 0.81$)$ & $0.97(0.78$ to 1.20$)$ & 1.03 (0.81 to 1.33$)$ & 0.69 \\
\hline $\begin{array}{l}\text { Cerebrovascular disease } \\
(\mathrm{n}=1604)\end{array}$ & $0.99(0.77$ to 1.27$)$ & $0.93(0.76$ to 1.13$)$ & $0.91(0.76$ to 1.10$)$ & $0.82(0.66$ to 1.02$)$ & 0.05 \\
\hline $\begin{array}{l}\text { Violence/accidents** } \\
(\mathrm{n}=1044)\end{array}$ & $1.11(0.85$ to 1.44$)$ & 1.09 (0.88 to 1.35$)$ & $1.18(0.97$ to 1.44$)$ & 1.37 (1.09 to 1.71$)$ & 0.005 \\
\hline Suicide ${ }^{* *}(n=231)$ & 1.31 (0.81 to 2.12 ) & 1.33 (0.87 to 2.01$)$ & 1.44 (0.97 to 2.13$)$ & 1.68 (1.06 to 2.66$)$ & 0.01 \\
\hline Other diseases ${ }^{*}(n=8979)$ & 1.02 (0.92 to 1.12$)$ & $1.05(0.97$ to 1.14$)$ & 1.05 (0.98 to 1.14$)$ & $1.09(1.00$ to 1.18$)$ & 0.02 \\
\hline
\end{tabular}

${ }^{*}$ Adjusts for model 3 variables: base model+mortality risk factors.

†Adjusts for model 3 variables: base model+cancer risk factors+mortality risk factors.

$\ddagger$ Adjusts for model 4 variables: base model+cancer risk factors+mortality risk factors+breast cancer risk factors (parity, age at first birth, hormone therapy use,

duration of hormone therapy, and history of benign breast disease).

§Adjusts for model 4 variables: base model+cancer risk factors+mortality risk factors+ovarian cancer risk factors (parity, tubal ligation, and hysterectomy).

TAdjusts for model 3 variables: sociodemographics+cardiovascular risk factors+mortality risk factors.

${ }^{\star *}$ Adjusts for model 3 variables: sociodemographics+violent/accident death risk factors+mortality risk factors. 
Table 5 | Ten year lag analysis of total and cause specific mortality by duration of oral contraceptive use (years) compared with never users among 117506 participants in the Nurses' Health Study, 1986-2012; hazard ratios (95\% confidence intervals)

\begin{tabular}{|c|c|c|c|c|c|c|}
\hline \multirow[b]{2}{*}{ Cause of death } & \multicolumn{5}{|c|}{ Duration of oral contraceptive use (years) } & \multirow[b]{2}{*}{ P for trend } \\
\hline & $\leq 1$ & $>1$ to $<2$ & $\geq 2$ to $<5$ & $\geq 5$ to $<10$ & $\geq 10$ & \\
\hline All causes ${ }^{*}(n=28200)$ & $1.02(0.98$ to 1.06$)$ & $1.01(0.94$ to 1.09$)$ & $1.01(0.97$ to 1.06$)$ & $1.03(0.99$ to 1.08$)$ & $1.04(0.98$ to 1.11$)$ & 0.11 \\
\hline Breast cancer† $(n=1749)$ & $0.98(0.84$ to 1.16$)$ & $1.02(0.79$ to 1.31$)$ & $0.93(0.78$ to 1.11$)$ & $1.06(0.89$ to 1.25$)$ & $1.12(0.88$ to 1.42$)$ & 0.34 \\
\hline $\begin{array}{l}\text { Breast cancer, further } \\
\text { adjusted } \neq\end{array}$ & $0.98(0.84$ to 1.16$)$ & $1.05(0.82$ to 1.36$)$ & $0.97(0.81$ to 1.16$)$ & $1.13(0.95$ to 1.35$)$ & $1.22(0.96$ to 1.55$)$ & 0.04 \\
\hline Ovarian cancert $(n=700)$ & $0.86(0.67$ to 1.11$)$ & $0.89(0.59$ to 1.33$)$ & $0.97(0.75$ to 1.25$)$ & $0.68(0.50$ to 0.92$)$ & $0.68(0.45$ to 1.04$)$ & 0.008 \\
\hline $\begin{array}{l}\text { Ovarian cancer, further } \\
\text { adjusted§ }\end{array}$ & 0.85 (0.66 to 1.09$)$ & 0.87 (0.58 to 1.31$)$ & 0.95 (0.73 to 1.23$)$ & $0.68(0.50$ to 0.91$)$ & $0.70(0.45$ to 1.06$)$ & 0.01 \\
\hline $\begin{array}{l}\text { Cerebrovascular } \\
\text { disease } \mathbb{( n = 1 4 9 2 )}\end{array}$ & $0.74(0.60$ to 0.91$)$ & $0.87(0.60$ to 1.25$)$ & $0.93(0.74$ to 1.16$)$ & $0.91(0.72$ to 1.13$)$ & 1.09 (0.83 to 1.45$)$ & 0.89 \\
\hline $\begin{array}{l}\text { Violence/accidents }{ }^{* *} \\
(\mathrm{n}=840)\end{array}$ & $1.38(1.12$ to 1.71$)$ & 0.78 (0.50 to 1.22$)$ & $1.13(0.88$ to 1.45$)$ & $0.86(0.64$ to 1.14$)$ & 0.87 (0.58 to 1.29$)$ & 0.15 \\
\hline Suicide $^{* *}(n=140)$ & $1.18(0.69$ to 2.00$)$ & $1.12(0.50$ to 2.52$)$ & $1.60(0.97$ to 2.64$)$ & $0.78(0.40$ to 1.52$)$ & $1.58(0.77$ to 3.24$)$ & 0.60 \\
\hline Other diseases ${ }^{*}(n=8562)$ & 1.07 (0.99 to 1.15$)$ & $1.01(0.88$ to 1.16$)$ & 1.04 (0.95 to 1.13$)$ & $1.06(0.97$ to 1.16$)$ & 1.11 (0.99 to 1.25$)$ & 0.05 \\
\hline
\end{tabular}

${ }^{*}$ Adjusts for model 3 variables: base model+mortality risk factors.

†Adjusts for model 3 variables: base model+cancer risk factors+mortality risk factors.

$\ddagger$ Adjusts for model 4 variables: base model+cancer risk factors+mortality risk factors+breast cancer risk factors (parity, age at first birth, hormone therapy use, hormone therapy duration, and history of benign breast disease).

§Adjusts for model 4 variables: base model+cancer risk factors+mortality risk factors+ovarian cancer risk factors (parity, tubal ligation, and hysterectomy). TAdjusts for model 3 variables: sociodemographics+cardiovascular risk factors+mortality risk factors.

${ }^{* \star}$ Adjusts for model 3 variables: sociodemographics+violent/accident death risk factors+mortality risk factors. 